\title{
Host response to human rhinovirus infection: toward targeted treatment strategies
}

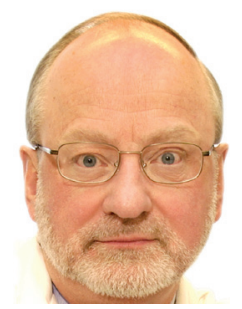

\author{
"Approximately 50\% of (chronic obstructive \\ pulmonary disease) exacerbations are associated \\ with viral infections, and (the human rhinovirus) is, \\ again, the dominant viral pathogen..."
}

David Proud, PhD

Institute of Infection, Immunity \& Inflammation, Department of Physiology \& Biophysics, University of Calgary Faculty of Medicine, 3330 Hospital Drive NW, Calgary, Alberta T2N 4N1, Canada = Tel.: +1 4032103816 - Fax: +1 4032700692 = dproud@ucalgary.ca

Human rhinoviruses (HRVs) are responsible for up to $50 \%$ of common colds experienced annually [1]. Although these infections are usually mild and self-limiting, complications of HRV infections cause substantial morbidity in susceptible individuals. In addition to complications such as sinusitis or otitis media [2-5], respiratory viral infections are a major trigger for exacerbations of lower airway diseases, such as chronic obstructive pulmonary disease (COPD) and asthma [6]. Acute exacerbations of asthma and COPD cause significant morbidity and mortality, and account for over half of the total healthcare costs for each disease $[7,8]$. HRV infections account for approximately $60 \%$ of virally induced exacerbations of asthma [9-12]. Approximately 50\% of COPD exacerbations are associated with viral infections, and HRV is, again, the dominant viral pathogen $[13,14]$. COPD exacerbations triggered by viral infections are more severe, and have longer recovery times than those linked solely to bacteria [13]. Thus, HRV-induced exacerbations of lower airway diseases are a major healthcare burden.

There have been few studies in adults examining treatment of exacerbations of known viral etiology, but studies in children with viral bronchiolitis suggest that current therapies used to treat asthma and COPD are of limited benefit in virally induced disease. Bronchodilators produce modest, short-term improvement but do not affect rates or duration of hospitalization [15,16]. Corticosteroids are ineffective in the treatment of HRV-induced colds [17,18], and asthmatics with prominent sputum neutrophils, suggestive of viral etiology, are poorly responsive to inhaled corticosteroids [19]. In addition, inhaled corticosteroids did not significantly reduce the increased lower airway inflammation in asthmatic subjects after HRV infection [20]. Moreover, administration of prednisolone to children hospitalized with viral bronchiolitis did not reduce the duration of hospitalization [21]. Thus, while corticosteroids may reduce exacerbation frequency by helping to maintain better asthma control, there is little evidence that they are effective in combating virally induced exacerbations of asthma once they occur. Similarly, there is mixed evidence regarding the ability of inhaled corticosteroids to reduce exacerbations of COPD [22,23]. Although a pilot study suggested that the leukotriene receptor antagonist, montelukast, might have efficacy in reducing symptoms of postviral bronchiolitis, a larger study failed to confirm this effect [24].

Conventional treatments targeting specific symptoms of colds have consistent, but modest, effects on the symptom being targeted. Thus, topical anticholinergic drugs [25], or older antihistamines with anticholinergic effects [26], tend to reduce rhinorrhea by approximately $25-30 \%$, and oral adrenergic agents have modest effects on nasal congestion. Overall, however, modest efficacy and, in some instances, troublesome side effects limit the usefulness of these approaches [27]. Clearly, therefore, new approaches to control the pathogenesis of HRV infections are required.

One strategy that has been explored is to target HRV binding, replication and spreading. The majority of HRV serotypes utilize intercellular adhesion molecule (ICAM)-1 as a cell-surface receptor [28], while the remainder of serotypes use members of the low-density lipoprotein (LDL) receptor family to gain cell entry. A soluble form of ICAM-1 (sICAM-1) administered intranasally, six times daily, to subjects beginning either $7 \mathrm{~h}$ before or $12 \mathrm{~h}$ after experimental HRV infection reduced symptom scores

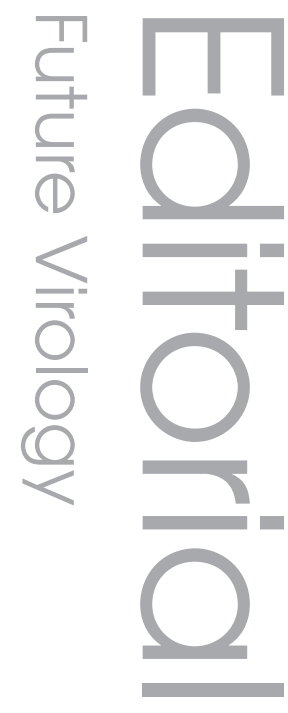

"...HRV-induced exacerbations of lower airway diseases are a major healthcare burden."

\section{future
medicine}




\footnotetext{
"At present, however, no antiviral agents are approved for the treatment of HRV infections or their complications."
}

and nasal secretion weights, and reduced viral titer [29]. A similar proof-of-concept was also established using soluble fragments of the LDL receptor, which inhibited infection [30]. Practical issues of dosing and cost, however, have limited the clinical utility and development of these biological inhibitors of receptor binding. Capsidbinding drugs that bind to the hydrophobic pocket at the bottom of the canyon region of the viral capsid to modulate attachment of the virus to its receptor and/or subsequent uncoating, and cell entry of the viral genome, have also been studied. One such compound, pleconaril, modestly reduced the duration of HRV infections and symptom scores, but concerns arose, as this compound was found to induce cytochrome P450 enzymes [31]. Inhibitors of the picornavirus 3C protease, which is essential for viral replication owing to its role in cleavage of the viral polyprotein, have also been studied. One compound, ruprintrivir, was tested as an intranasal spray, and reduced viral titer and significantly inhibited symptom scores by one-third [32]. This suggests that inhibition of $3 \mathrm{C}$ protease is a viable approach for therapy, and development of such compounds continues. At present, however, no antiviral agents are approved for the treatment of HRV infections or their complications.

A second, largely unexplored potential therapeutic approach is to modulate the host response to HRV infection. The airway epithelial cell is the primary site of HRV infection [33,34], and it is known that HRV can spread to the epithelium of the lower respiratory tract [35]. By contrast to other viral types, however, HRV causes no overt epithelial toxicity either in vitro or in vivo [36,37]. Thus, it is likely that viral alterations of epithelial cell biology trigger the inflammatory changes that initiate the pathogenic response to the virus, and that it is the host response to HRV, rather than the virus itself, that is responsible for symptomatic outcomes. In support of this, HRV infection has been shown to induce epithelial production of a number of individual proinflammatory cytokines and chemokines [36,38-41], as well as molecules associated with host antiviral and immune responses [42,43]. Several of these molecules have also been detected in airway secretions during in vivo HRV infections [38,40,42-44]. Although these studies implicated individual proteins in the response to HRV, a better understanding of the pathogenesis of HRV infections has recently been achieved as a result of a comprehensive assessment of epithelial gene expression changes in response to HRV infection in vivo. Nasal epithelial scrapings were obtained before and 2 days after inoculation with HRV or medium without virus, and total RNA was extracted. Microarray chips were used to analyze changes in the expression of more than 47,000 transcripts. After infection, 11,887 transcripts representing 6530 genes were found to be significantly different between the infected and placebo-inoculated groups [45]. Using an arbitrary threshold of a twofold change, 471 transcripts showed at least a twofold increase in expression, whereas 201 transcripts were decreased to levels of 0.5 -fold or less, relative to control. There were few obvious functional groupings in the genes that were downregulated, but a substantial number of highly induced genes fell into discrete functional categories. These included genes for a number of chemokines of both the $\mathrm{C}-\mathrm{C}$ and $\mathrm{C}-\mathrm{X}-\mathrm{C}$ families. Although some of these genes were anticipated based on prior literature, some were unexpected and are candidates for further study. Other groups included signaling molecules, molecules involved in adhesion and airway remodeling, and interferon-inducible genes. Overlapping with this latter category were a variety of gene products with known or potential antiviral functions. These data provide the first complete 'roadmap' of the host response to HRV infections, and identify several novel genes that require further study to evaluate their roles. The data also suggest several potential therapeutic approaches. One would be to target key proinflammatory chemokines to limit the airway inflammation induced by HRV infection. However, this approach requires a clear understanding of which mediators and inflammatory cell populations are inducing excessive inflammation, and which are essential for inducing antiviral immune responses. As neutrophil numbers correlate with symptom severity, both in simple colds and during viral exacerbations of asthma [46,47], one may suggest that inhibitors of neutrophil chemoattractants, such as CXCL8 and CXCL5, provide a therapeutic approach. Given the complexity of the proinflammatory response, however, targeting individual chemokines or chemokine receptors may be both time consuming and relatively ineffective. Other strategies could involve targeting HRV-specific epithelial signaling pathways. Perhaps the most promising approach, however, is to enhance the endogenous expression of, or to exogenously supplement, key host antiviral defense pathways. For example, the two genes most upregulated among the antiviral products in the gene array were viperin and type II nitric oxide synthase (iNOS). The same study demonstrated for the 
first time that viperin is, indeed, a component of the host antirhinovirus response, as knockdown of viperin led to a threefold increase in viral replication [45]. Interestingly, in subjects with experimental HRV infections, both epithelial iNOS and levels of airway-exhaled nitric oxide (NO) increase [43,48]. Importantly, subjects who show the greatest exhaled NO levels had the lowest symptoms and cleared the virus more rapidly [48]. Consistent with this effect, NO inhibits HRV replication in epithelial cells and can also inhibit HRV-induced chemokine production independently of its effects on replication [49-51]. Inhibition of chemokine production by $\mathrm{NO}$ in HRV-infected epithelial cells is due to NO-mediated inhibition of activation and nuclear translocation/binding of the transcription factors nuclear factor- $\kappa \mathrm{B}$ and interferon response factor-1 [51]. The broadranging inhibition of $\mathrm{HRV}$-induced epithelial chemokine production by NO, together with its effects on HRV replication, clearly suggests a potential therapeutic utility of $\mathrm{NO}$ donors in HRV infections.

In summary, therefore, recent insights into the pathogenesis of HRV infections strongly support the concept that modulating aspects of the host response to HRV represents a rational approach to identify new therapeutic strategies for the treatment of HRV infections and their lower airway complications.

\section{Financial \& competing interests disclosure \\ The author has no relevant affiliations or financial involvement with any organization or entity with a financial interest in or financial conflict with the sub- ject matter or materials discussed in the manuscript. This includes employment, consultancies, honoraria, stock ownership or options, expert testimony, grants or patents received or pending, or royalties. \\ No writing assistance was utilized in the production of this manuscript.}

\section{Bibliography}

1. Makela MJ, Puhakka T, Ruuskanen O et al.: Viruses and bacteria in the etiology of the common cold. J. Clin. Microbiol. 36, 539-542 (1998).

2. Gwaltney JM Jr, Philips CD, Miller RD, Riker DK: Computed tomographic study of the common cold. N. Engl. J. Med. 330, 25-30 (1994).

3. Pitkäranta A, Arruda E, Malmberg H, Hayden FG: Detection of rhinovirus in sinus brushings of patients with acute communityaquired sinusitis by reverse transcription-PCR J. Clin. Microbiol. 35, 1791-1793 (1997).

4. Arola M, Ziegler T, Puhakka H et al.: Rhinovirus in otitis media with effusion. Ann. Otol. Rhinol. Laryngol. 99, 451-453 (1990).

5. Pitkaranta A, Virolainen A, Jero J et al: Detection of rhinovirus, respiratory syncytial virus, and coronavirus infections in acute otitis media by reverse transcription polymerase chain reaction. Pediatrics 102, 291-295 (1998).

6. Proud D, Chow C-W: Role of viral infections in asthma and chronic obstructive pulmonary disease. Am. J. Respir. Cell Mol. Biol. 35, 513-518 (2006).

7. Smith DH, Malone DC, Lawson KA et al.: A national estimate of the economic costs of asthma. Am. J. Respir. Crit. Care Med. 156, 787-793 (1997).

8. Pauwels RA, Buist AS, Calverley PMA et al: : Global strategy for the diagnosis, management, and prevention of chronic obstructive pulmonary disease.
NHLBI/WHO global initiative for chronic obstructive lung disease (GOLD) workshop summary. Am. J. Respir. Crit. Care Med. 163, 1256-1276 (2001).

9. Johnston SL, Pattemore PK, Sanderson G et al.: Community study of role of viral infections in exacerbations of asthma in 9-11 year old children. Br. Med. J. 310, 1225-1228 (1995).

10. Khetsuriani N, Kazerouni NN, Erdman DD et al:: Prevalence of viral respiratory tract infections in children with asthma. J. Allergy Clin. Immunol. 119, 314-321 (2007).

11. Nicholson KG, Kent J, Ireland DC: Respiratory viruses and exacerbations of asthma in adults. Br. Med. J. 307, 982-986 (1993).

12. Kistler A, Avila PC, Rouskin S et al:: Pan-viral screening of respiratory tract infections in adults with and without asthma reveals unexpected human coronavirus and human rhinovirus diversity. J. Infect. Dis. 196, 817-825 (2007).

13. Seemungal T, Harper-Owen R, Bhowmik A et al.: Respiratory viruses, symptoms and inflammatory markers in acute exacerbations and stable chronic obstructive pulmonary disease. Am. J. Respir Crit. Care Med. 164, 1618-1623 (2001).

14. Rohde G, Wiethege A, Borg I et al.: Respiratory viruses in exacerbations of chronic obstructive pulmonary disease requiring hospitalisation: a case-control study. Thorax 58, 37-42 (2003).
15. Patel H, Gouin S, Platt RW: Randomized, double-blind, placebo-controlled trial of oral albuterol in infants with mild-to-moderate acute bronchiolitis. J. Pediatr. 142, 509-514 (2003).

16. Schindler M: Do bronchodilators have an effect on bronchiolitis? Crit. Care 6, 111-112 (2002).

17. Farr BM, Gwaltney JM Jr, Hendley JO et al.: A randomized controlled trial of glucocorticoid prophylaxis against experimental rhinovirus infection. J. Infect. Dis. 162, 1173-1177 (1990).

18. Gustafson LM, Proud D, Hendley JO et al.: Oral prednisone therapy in experimental rhinovirus infections. J. Allergy Clin. Immunol. 97, 1009-1014 (1996).

19. Green RH, Brightling CE, Woltmann G et al: : Analysis of induced sputum in adults with asthma: identification of subgroup with isolated sputum neutrophilia and poor response to inhaled corticosteroids. Thorax 57, 875-879 (2002).

20. Grunberg K, Sharon RF, Sont JK et al:: Rhinovirus-induced airway inflammation in asthma: effect of treatment with inhaled corticosteroids before and during experimental infection. Am. J. Respir. Crit. Care Med. 164, 1816-1822 (2001).

21. Jartti T, Lehtinen P, Vanto T et al: Evaluation of the efficacy of prednisolone in early wheezing induced by rhinovirus or respiratory syncytial virus. Pediatr. Infect. Dis. J. 25, 482-488 (2006). 
22. Fan VS, Bryson CL, Curtis JR et al.: Inhaled corticosteroids in chronic obstructive pulmonary disease and risk of death and hospitalization. Am. J. Respir. Crit. Care Med. 168, 1488-1494 (2003).

23. Wedzicha JA, Donaldson GC: Exacerbations of chronic obstructive pulmonary disease. Respir. Care 48, 1204-1213 (2003).

24. Bisgaard H, Flores-Nunez A, Goh A et al.: Study of montelukast for the treatment of respiratory symptoms of postrespiratory synytial cirus bronchiolitis in children. Am. J. Respir. Crit. Care Med. 178, 845-860 (2008).

25. Hayden FG, Diamond L, Wood PB et al:: Effectiveness and safety of intranasal ipratropium bromide in common colds: a randomized, double-blind, placebo controlled study. Ann. Intern. Med. 125, 89-97 (1996).

26. Gwaltney JMJ, Druce HM: Efficacy of bromopheniramine maleate for the treatment of rhinovirus colds. Clin. Infect. Dis. 25, 1188-1194 (1997).

27. Turner RB: The treatment of rhinovirus infections: progress and potential. Antiviral Res. 49, 1-14 (2001).

28. Greve JM, Davis G, Meyer AM et al: The major human rhinovirus receptor is ICAM-1. Cell 56, 839-847 (1989).

29. Turner RB, Wecker MT, Pohl G et al:: Efficacy of tremacamra, a soluble intercellular adhesion molecule 1 , for experimental rhinovirus infection. JAMA 281, 1797-1804 (1999).

30. Marlovits TC, Zechmeister T, Schwihla H et al.: Recombinant soluble low-density lipoprotein receptor fragment inhibits common cold infection. J. Mol. Recognit. 11, 49-51 (1998).

31. Hayden FG, Herrington DT, Coats TL et al.: Efficacy and safety of oral pleconaril for treatment of colds due to picornaviruses in adults: results of 2 double-blind, randomized, placebo-controlled trials. Clin. Infect. Dis. 36, 1523-1532 (2003).

32. Hayden FG, Turner RB, Gwaltney JM et al: : Phase II, randomized, double-blind, placebo-controlled studies of ruprintrivir nasal spray 2-percent suspension for prevention and treatment of experimentally induced rhinovirus colds in healthy volunteers. Antimicrob. Agents Chemother. 47, 3907-3916 (2003).
33. Bardin PG, Johnston SL, Sanderson G et al: : Detection of rhinovirus infection of the nasal mucosa by oligonucleotide in situ hybridization. Am. J. Respir. Cell Mol. Biol. 10, 207-213 (1994).

34. Arruda E, Boyle TR, Winther B et al.: Localization of human rhinovirus replication in the upper respiratory tract by in situ hybridization. J. Infect. Dis. 171, 1329-1333 (1995).

35. Mosser AG, Vrtis R, Burchell L et al.: Quantitative and qualitative analysis of rhinovirus infection in bronchial tissues. Am. J. Respir. Crit. Care Med. 171, 645-651 (2005).

36. Subauste MC, Jacoby DB, Richards SM, Proud D: Infection of a human respiratory epithelial cell line with rhinovirus. Induction of cytokine release and modulation of susceptibility to infection by cytokine exposure. J. Clin. Invest. 96, 549-557 (1995).

37. Winther B, Brofeldt S, Christensen B, Mygind N: Light and scanning electron microscopy of nasal biopsy material from patients with naturally acquired common colds. Acta. Otolaryngol. (Stockh.) 97, 309-318 (1984).

38. Donninger $\mathrm{H}$, Glashoff R, Haitchi H-M et al.: Rhinovirus induction of the CXC chemokine epithelial-neutrophil activating peptide-78 in bronchial epithelium. J. Infect. Dis. 187, 1809-1817 (2003).

39. Schroth MK, Grimm E, Frindt $\mathrm{P}$ et al.: Rhinovirus replication causes RANTES production in primary bronchial epithelial cells. Am. J. Respir. Cell Mol. Biol. 20, 1220-1228 (1999).

40. Spurrell JCL, Wiehler S, Zaheer RS et al.: Human airway epithelial cells produce IP-10 (CXCL10) in vitro and in vivo upon rhinovirus infection. Am. J. Physiol. Lung Cell. Mol. Physiol. 289, L85-L95 (2005).

41. Terajima M, Yamaya M, Sekizawa K et al.: Rhinovirus infection of primary cultures of human tracheal epithelium: role of ICAM-1 and IL-1ß. Am. J. Physiol. 273, L749-L759 (1997).

42. Proud D, Sanders SP, Wiehler S: Human rhinovirus infection induces airway epithelial cell production of human $\beta$-defensin- 2 both in vitro and in vivo. J. Immunol. 172, 4637-4645 (2004).
43. Sanders SP, Siekierski ES, Richards SM et al: Rhinovirus infection induces expression of type 2 nitric oxide synthase in human respiratory epithelial cells in vitro and in vivo. J. Allergy Clin. Immunol. 107, 235-243 (2001).

44. Proud D, Gwaltney JM Jr, Hendley JO et al.: Increased levels of interleukin-1 are detected in nasal secretions of volunteers during experimental rhinovirus colds. J. Infect. Dis. 169, 1007-1013 (1994).

45. Proud D, Turner RB, Winther B et al.: Gene expression profiles during in vivo human rhinovirus infection: insights into the host response. Am. J. Respir. Crit. Care Med. 178, 962-968 (2008).

46. Naclerio RM, Proud D, Lichtenstein LM et al:: Kinins are generated during experimental rhinovirus colds. J. Infect. Dis. 157, 133-142 (1988).

47. Wark PAB, Johnston SL, Moric I et al. Neutrophil degranulation and cell lysis is associated with clinical severity in virusinduced asthma. Eur. Respir. J. 19, 68-75 (2002).

48. Sanders SP, Proud D, Siekierski ES et al.: Role of nasal nitric oxide in the resolution of experimental rhinovirus infection. J. Allergy Clin. Immunol. 113, 697-702 (2004).

49. Sanders SP, Siekierski ES, Porter JD et al.: Nitric oxide inhibits rhinovirus-induced cytokine production and viral replication in a human respiratory epithelial cell line. J. Virol. 72, 934-942 (1998).

50. Sanders SP, Kim J, Connolly KR et al.: Nitric oxide inhibits rhinovirus-induced GM-CSF production in bronchial epithelial cells. $A m$. J. Respir. Cell Mol. Biol. 24, 317-325 (2001).

51. Koetzler R, Zaheer RS, Wiehler S et al.: Nitric oxide inhibits human rhinovirusinduced transcriptional activation of CXCL10 in airway epithelial cells. J. Allergy Clin. Immunol. 123, 201-208 (2009).

\section{Affiliation}

- David Proud, PhD Institute of Infection, Immunity \& Inflammation, Department of Physiology \& Biophysics, University of Calgary Faculty of Medicine, 3330 Hospital Drive NW, Calgary, Alberta T2N 4N1, Canada Tel.: +1 4032103816 ; Fax: +1 403270 0692; dproud@ucalgary.ca 